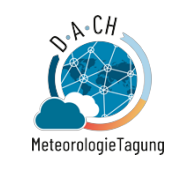

Kurzfassungen der Meteorologentagung DACH

DACH2022-217, 2022, updated on 10 Jan 2022

https://doi.org/10.5194/dach2022-217

DACH2022

(C) Author(s) 2022. This work is distributed under

the Creative Commons Attribution 4.0 License.

\title{
Impact of aerosols on photovoltaic energy production using a spectrally resolved model chain: A case study for Sub-Sahara West- Africa
}

\author{
Stefanie Meilinger ${ }^{1}$, Anna Herman-Czezuch ${ }^{1}$, Armelle Zemo Mekeng ${ }^{1}$, Nicola Kimiaie ${ }^{1,2}$, and James \\ Barry ${ }^{1}$ \\ ${ }^{1}$ Bonn-Rhein-Sieg University of Applied Sciences, International Center for Sustainable Development, Sankt Augustin, Germany \\ (stefanie.meilinger@h-brs.de) \\ ${ }^{2}$ HYREF GmbH, Herten, Germany
}

West Africa has a great potential for the application of solar energy systems, as it combines high levels of solar irradiance with a lack of energy production. Southern West Africa is a region with a very high aerosol load. Urbanization, uncontrolled fires, traffic as well as power plants and oil rigs lead to increasing anthropogenic emissions. The naturally circulating north winds bring mineral dust from the Sahel and Sahara and monsoons - sea salt and other oceanic compounds from the south. The EU-funded Dynamics-Aerosol-Chemistry-Cloud Interactions in West Africa (DACCIWA) project (2014-2018), dlivered the most complete dataset of the atmosphere over the region to date. In our study, we use in-situ measured optical properties of aerosols from the airborne campaign over the Gulf of Guinea and inland, and from ground measurements in coastal cities.

Based on an analysis of the aerosol optical properties form the DACCIWA measurement campaign, the impact of aerosol on PV power is investigated for polycrystalline silicon and amorphous silicon technology using a spectrally resolved model chain. The model considers both spectral effects on global irradiance due to different aerosol properties as well as the spectral response of different PV technologies. First, the contribution of various aerosol types (mineral dust, biomass burning and anthropogenic pollution) derived from a post-project classification is studied. Subsequently, differences between these imaginary aerosol scenarios and a real case during a biomass burning outbreak on July 13, 2016 in Benin are presented. The results show that aerosol emissions due to the biomass outbreak on the day of the case study in Cotonou lead to solar flux losses of up to $55 \%$ and photovoltaic power reduction of up to $81 \%$ for the polycrystalline cell and $78 \%$ for the amorphous cell. The relative impact of aerosols differs depending on aerosol type and concentration, being larger for low solar zenith angles than at noon. For the situation studied in Cotonou, Benin, we are able to show that the inclusion of spectral aspects leads to a significant effect when calculating the PV power. Comparing the effects of aerosols on the photovoltaic power of the two technologies, we find that the amorphous cell suffers a greater reduction in power during the morning and evening hours - when there is more diffuse irradiance - of $36 \%$ than the polycrystalline cell $(27 \%)$. Conversely, in the middle of the day, we observe greater PV power reduction of the polycrystalline cell of $12 \%$ compared to the amorphous cell ( $8 \%)$.

Acknowledgements: Funding was provided by the German BMWi under contract 0350009A and BMBF under contract 03SF0567A-. 